\title{
Development and Application of a Rural Intercity Demand Model
}

\author{
Frederic D. Fravel and Reyes Barboza, Jr. \\ KFH Group, Inc.
}

\begin{abstract}
This paper describes the development of a demand model to estimate ridership for rural intercity bus services in the United States. The need for such a model and the approach used in developing it are described. Two models were developed, one a regression equation calibrated on data from a survey of rural intercity services, and the other using a trip rate developed from National Household Travel Survey data. Both models are included in a toolkit that also includes user information and population data. The paper then compares the ridership predictions made using the model with actual experience on rural intercity routes in Washington State and illustrates how it can be used as part of a statewide assessment for Vermont. Conclusions about its applicability and directions for future research are presented.
\end{abstract}

\section{Background}

The national intercity bus network has been contracting in coverage for many years, but a substantial shift away from services in rural areas began with the passage of the Bus Regulatory Reform Act in 1982. Following the loss of substantial amounts of rural intercity bus service subsequent to regulatory reform, the Intermodal Surface Transportation Efficiency Act (ISTEA), passed by Congress in 1991, created the Section 18(i) program of assistance for rural intercity services, offering operating, capital, and administrative funding to the states for use in maintaining or developing rural intercity services. This program was subsequently codified as 
Section 5311(f). SAFETEA-LU (Safe, Accountable, Flexible, Efficient Transportation Equity Act: A Legacy for Users) continued the program and added a requirement that the states consult with stakeholders (including intercity bus operators) when deciding whether or not to use the funding for intercity bus (as opposed to other rural) needs. The most recent transportation authorizing legislation, MAP-21, included statutory language supporting the in-kind match.

It should be noted that this program, and the demand model described here, relate to rural intercity bus services but not to the expanding express services. In recent years, a major expansion of intercity bus services has taken place as "curbside" express bus services have provided increased frequencies of non-stop (or limited stop) services. Initially beginning with express services linking the "Chinatown" areas of major cities in the northeast, this type of service offers Internet reservations, discount fares, curbside pickup and dropoff, and express service with few, if any, intermediate stops. This bus service model has now been developed and expanded by major carriers. Greyhound Lines joined with Peter Pan Bus Lines to create BoltBus services between major cities in the northeast (and now between Seattle and Portland). Coach USA, a subsidiary of Stagecoach of the United Kingdom, imported its Megabus service model from the United Kingdom. These services operate out of a number of hubs in the northeast, southeast, midwest and now Texas. Greyhound is now providing a similar service on many city pairs, branded Greyhound Express. However, to this point, these services have benefited large cities or major college towns, and the expansion of frequency has had little impact on small towns in rural areas (unless home to a major university). ${ }^{1}$

The availability of this funding and the existence of State-funded programs in several states calls for a tool to identify which potential rural intercity feeder markets make sense based on the projected ridership and revenue. State and regional planners, bus companies, and rural transit operators need a demand model, rule of thumb, or similar tool that is based on recent experiences to assist in determining the likely intercity-related ridership and the impact of different arrangements on the potential demand. Most basically, a way to estimate intercity trip demand from rural areas to larger cities is needed to help in the design of projects that will link rural areas with major urban areas and the national intercity network. The level of demand obviously varies with population, and probably with frequency and service design, and is a major consideration in service design issues.

The need for such a tool led to a Transit Cooperative Research Program (TCRP) project to create a rural intercity demand model. The results of that effort are now 
available in TCRP Report 147, "Toolkit for Estimating Demand for Rural Intercity Services." ${ }^{2}$ This paper provides an overview of the results of the research effort, the toolkit developed to facilitate user application of the results, and finally it presents examples illustrating the application of the model and toolkit to estimate demand for rural intercity services in Washington State and Vermont. This paper is intended to inform the reader about the existence of this research, and also to present some additional information about the results of its application.

\section{Purpose of the Project}

The objective of this research project was to develop a sketch planning guide and supporting tools that could be used by state transportation department program managers and public and private rural intercity bus service providers to forecast demand for rural intercity bus services.

The potential audience for this research includes state agency program officials and staff, planners, local officials, existing and potential public and private operators, and sponsors of rural intercity bus service.

\section{Review of Previous Demand Estimation Methods}

TCRP Report 147 documents a number of approaches to the estimation of rural intercity bus demand. ${ }^{3}$ During the 1980s, as the bus industry restructured following deregulation, the interest in potential state or federal programs to provide operating or capital assistance led to a number of efforts to develop demand models. More recent efforts at planning have used earlier models or other sketchplanning techniques to estimate potential ridership. The approaches used in the various studies have varied according to the desired application and the available data. Approaches have included the use of:

- Per capita intercity trip generation rates

- Ridership on comparable services

- Historical data

- Stop-level regression models

- Route-level regression models

- City-pair regression models, and

- Network models 
Several applications of these approaches are documented in the TCRP report, including the use of trip rates in the Washington intercity bus plan and the use of a regression model to estimate demand and revenue for a Virginia study.

\section{Inventory of Existing Rural Intercity Routes and Ridership}

An important and significant part of the effort to develop a demand model for rural intercity bus ridership involved an effort to identify current or recent rural intercity bus services, their characteristics, and their ridership. These basic data elements are critical to the ability to calibrate or evaluate any type of technique for estimating ridership. Chapter 3 of TCRP Report 147 describes the type of data sought and the survey methodology to collect the data.

Initially, all the service characteristics that could potentially affect ridership were identified as was the list used to develop a survey for completion by the agency or firm operating the service. Initial pilot tests of the survey resulted in a shortened version.

A second step involved the identification of rural intercity services. Because it was anticipated that the resulting models would be used primarily to estimate ridership on services funded with Section 5311(f) operating assistance, the approach taken involved contacting the transit programs in all state departments of transportation to determine if they had provided operating funding for rural intercity bus service in the past three years. If so, we requested contact information for the provider and also any information available at the state level on service characteristics or ridership. Additional effort went into using other data sources such as websites and industry schedule guides to develop service characteristics. The effort involved in identifying the state contacts, contacting carriers, and obtaining service and ridership data was significant.

The result was a database of routes, with data on the operator, route endpoints, stops, route length, frequency, fare (and/or fare per mile), corridor population, destination population, and presence of potential key generators (college or university, major medical center, airport, etc.). A total of 133 routes were identified, with annual ridership data available for all but 18 . 


\section{Rural Intercity Bus Classification Scheme}

With the database of routes and route characteristics in hand, the study team developed a classification of the services in an effort to combine services with similar characteristics into separate classes. This was done to identify potential commonalities that could assist in the development of demand estimation techniques, or to facilitate the development of separate demand tools for different types of services. An initial classification was developed based on the type of provider. Three classes were developed:

- Services that are comparable to traditional intercity bus services

- Services that are regional in character, provided by private firms

- Services that are regional but operated by public transit providers

For each class, the characteristics of that class were identified based on the data from the survey. Following the efforts to define these classifications more fully to focus on connectivity to the national intercity bus network as a key element of the definition of intercity service, additional data were needed on many of the services to determine if a passenger could use the service (included in the database) to access the national intercity bus network. The revised classification included 99 routes, all considered "rural intercity" for the purposes of this study.

\section{Development of a Sketch-Planning Tool}

The process of developing demand estimation tools, even with a fairly large data set, proved to be more problematic than originally thought. Initially, the research team considered all desired characteristics of a model or toolkit. This helped to set the goals for the effort but also made it apparent how difficult it might be to address all potential issues that might be faced by a user. This project was intended only to develop a demand estimation tool or process, not to develop a full planning process.

Two basic development approaches were undertaken. One involved the effort to develop trip rates for the routes and corridors included in the database, potentially including route length as a factor to adjust trip rates. However, when no discernible pattern of trip rates could be developed, several issues were identified. One was the impact of intermediate stops on route-level ridership, and the other was the difficulty in determining the appropriate corridor population to calculate a trip rate when a large metropolitan area is part of the corridor. In such cases, a trip rate that includes the large population will be very different from a route with only 
rural stops. Eventually, it was decided to determine if trip rates from a separate source could be used to develop a tool that would have predictive value. A special run of the National Household Travel Survey (NHTS) focusing on the long-distance trips made by persons in non-urbanized areas was requested. The resulting data were also classified by income and region. Information on mode share from several sources was used to develop trip rates; the one percent mode share produced ridership estimates most similar to the survey data, and it was chosen for use in the trip rate model or tool.

The alternative approach taken was an effort to develop a multiple regression model using the database. Initial efforts produced models with limited explanatory power. Evaluation of these initial results led to a disaggregation of the population data variable, which was corridor population, into urbanized and non-urbanized components. Finally, improved results came from using populations for Urbanized Areas (over 50,000 population), Urban Clusters (2,500 to 50,000 persons), and Census Designated Places (under 2,500 persons). These provide populations that are not necessarily limited to municipal boundaries.

Analysis of residuals led to continued work with the regression model, this time reducing the cases to eliminate routes that were outliers. A separate variable for the number of stops was also included in the data set. With the elimination of outliers, the data set was reduced to 58 usable cases, and the distinction between standard intercity bus service and regional rural intercity bus service classes was made into a categorical variable.

Continued work with stepwise regression eventually resulted in the best fitting model:

$$
\begin{gathered}
\text { Ridership }=-2803.536+0.194 \text { (Average Origin Population) }+ \\
314.734 \text { (the number of stops on the route) }+ \\
4971.668 \text { (airport service or connection) }+ \\
5783.653 \text { (service provided by intercity provider) } \\
R^{2}=0.712 \text {, Adjusted } R^{2}=0.690^{4}
\end{gathered}
$$

Where,

Ridership = annual one-way passenger boardings

Average origin population $=$ sum of the populations of origin points (all points on the route except that with the largest population)

Number of stops $=$ count of points listed in public timetables as stops 
Airport service or connection $=$ route serves an airport with commercial service either directly or with one transfer at a common location

Intercity provider = service operated by a carrier meeting the definition of an intercity bus carrier. ${ }^{5}$

A subsequent effort used the residuals ${ }^{6}$ from the regression model to adjust the trip rate model results, improving the results slightly over the pure trip rate model, as shown in Table 1:

Table 1. Accuracy of Trip Rate and Regression Models

\begin{tabular}{|l|c|c|c|}
\hline & $\begin{array}{c}\text { 1\% Trip Rate } \\
\text { Prediction }\end{array}$ & $\begin{array}{c}\text { Adj. 1\% Trip } \\
\text { Rate Prediction }\end{array}$ & $\begin{array}{c}\text { Regression } \\
\text { Prediction }\end{array}$ \\
\hline Within 50\% of actual ridership & $45.60 \%$ & $54.40 \%$ & $59.60 \%$ \\
\hline Within 10\% of actual ridership & $14.00 \%$ & $15.80 \%$ & $17.50 \%$ \\
\hline Within 5\% of actual ridership & $8.80 \%$ & $5.30 \%$ & $5.30 \%$ \\
\hline
\end{tabular}

Both of these techniques are more accurate for current rural intercity bus services than the demand models estimated for NCHRP in 1980.' They represent a pragmatic approach that makes use of available data to produce initial estimates of potential ridership for new rural services. The regression model has the correct signs (e.g., ridership increases with a higher population base, etc.), and is plausible given general knowledge about travel behavior. It reflects higher ridership for intermodal connectivity to airports and for interlining. It uses population data as a key variable, but the impact of population is moderated by using the number of stops to calculate an average population per stop. This is plausible in that we expect ridership to be lower if the bus stops often to serve that population, which seems to reflect market preference for fewer stops.

The use of the NHTS trip rate data also involves making maximum use of the available data. It provides ridership estimates based entirely on population served, but it is calibrated, in a sense, through the selection of the mode choice factor to provide ridership estimates that most closely match the usage found in the data set. Regional variation is introduced through the use of regional trip rates. Finally, the 58-route data set was used to develop an adjustment factor that can be applied to the trip rate model results to further improve its results. The result is that the trip rate model and the regression model have comparable accuracy in terms of the percentage of time they will predict a ridership figure that is within a given percentage of the actual. However, they may not give the same answer. 
Both the difficulties experienced and the results suggest that over the past 30 years, rural intercity bus service has become much more specialized, with the remaining routes or services much more likely to be provided in areas with fairly unique demand characteristics. Neither model takes account of the overhead traffic (ridership originating in or destined to places beyond the endpoints of the particular route in question) that might result in ridership variance or other variables such as the presence of a large university or military base that might affect demand.

\section{Toolkit}

The major product of this project was intended to be an easy-to-use toolkit to assist planners in estimating ridership on rural intercity routes. It was decided that the tools would best be provided on a CD with the models and their calculations embedded so that users would not have to deal with formulas or look up tables but would merely need to input data for a proposed route to get the model estimates. Users desiring more information about the models and the data can refer to the technical report. The toolkit is, thus, a disk, and it provides the user with a discussion of its applicability, an overview of the elements included, a step-by-step process for estimating ridership (which includes preliminary aspects that would precede use of the models and the information that will be needed from the user), possible manual adjustments to improve accuracy, a detailed example of its application to a case, and a lookup database that provides ridership on comparable routes and a link to more descriptive data about the comparable routes.

\section{Comparison of Model Results to Experience- "Travel Washington"}

To illustrate the likely results if a state or regional planner uses the toolkit to estimate the demand for a rural intercity route, the final toolkit was used to estimate ridership on the four rural intercity routes funded by the Washington State Department of Transportation (WSDOT) under its Section 5311(f) rural intercity bus program. WSDOT has branded these services as "Travel Washington" statewide, with each corridor benefiting from a unique regional identity tied to local products. All four corridors connect with the national intercity bus network and offer interline ticketing. At the destination end, the routes also provide stops at Amtrak stations, local transit hubs, and, in one case, a major airport. 
For each route, the toolkit $C D$ was used following the accompanying directions. The population data for the corridor came from the CD, and the one-way route length for each route was obtained by using an Internet mapping program to plot the route with the stops as depicted on the WSDOT website. The only other data required are information about whether the route served an airport with commercial service and whether or not the route was operated by a national intercity bus carrier.

Table 2 presents the estimated ridership for each corridor, along with actual ridership. Note that each route has been operating for a different length of time. Overall, the obvious conclusion is that the regression model produces estimates that are much closer to the actual ridership than the trip rate results and that the regression estimates are reasonable for use in planning such services. Further investigation revealed that the high ridership on the Dungeness Line is largely due to the fact that visitors from Canada can access this route from the ferry and use it for service to Seattle, particularly the airport, which has extensive service. Also, the relatively high ridership on the Grape Line in part reflects continued growth; the ridership in the initial two years was closer to the regression estimate. It should be noted that the model does not necessarily represent the ridership at any particular time point following the initiation of service. The database used for calibration included routes that were continuations of existing intercity services, new routes, and routes that have been operating for several years. For that reason, the user might exercise caution in creating expectations that the forecast ridership would be achieved in an initial year or even two. However, the continued Grape Line ridership growth beyond forecast demand suggests that the estimate is not necessarily the ultimate limit on what may be achieved.

\section{Planning Application-Potential Rural Intercity Routes for Vermont}

A second illustration of potential use of the models can be found in recent work for the Vermont Agency of Transportation. Part of the update of its Public Transit Policy Plan analysis of transit needs found that the loss of rural intercity bus services had left many towns in the state with no direct intercity bus access to major out-of-state travel destinations. In some cases, regional rural public transit services developed primarily to meet commuter needs can be used to make trips within the state or to cities that continue to have intercity bus services. The loss has been dra- 


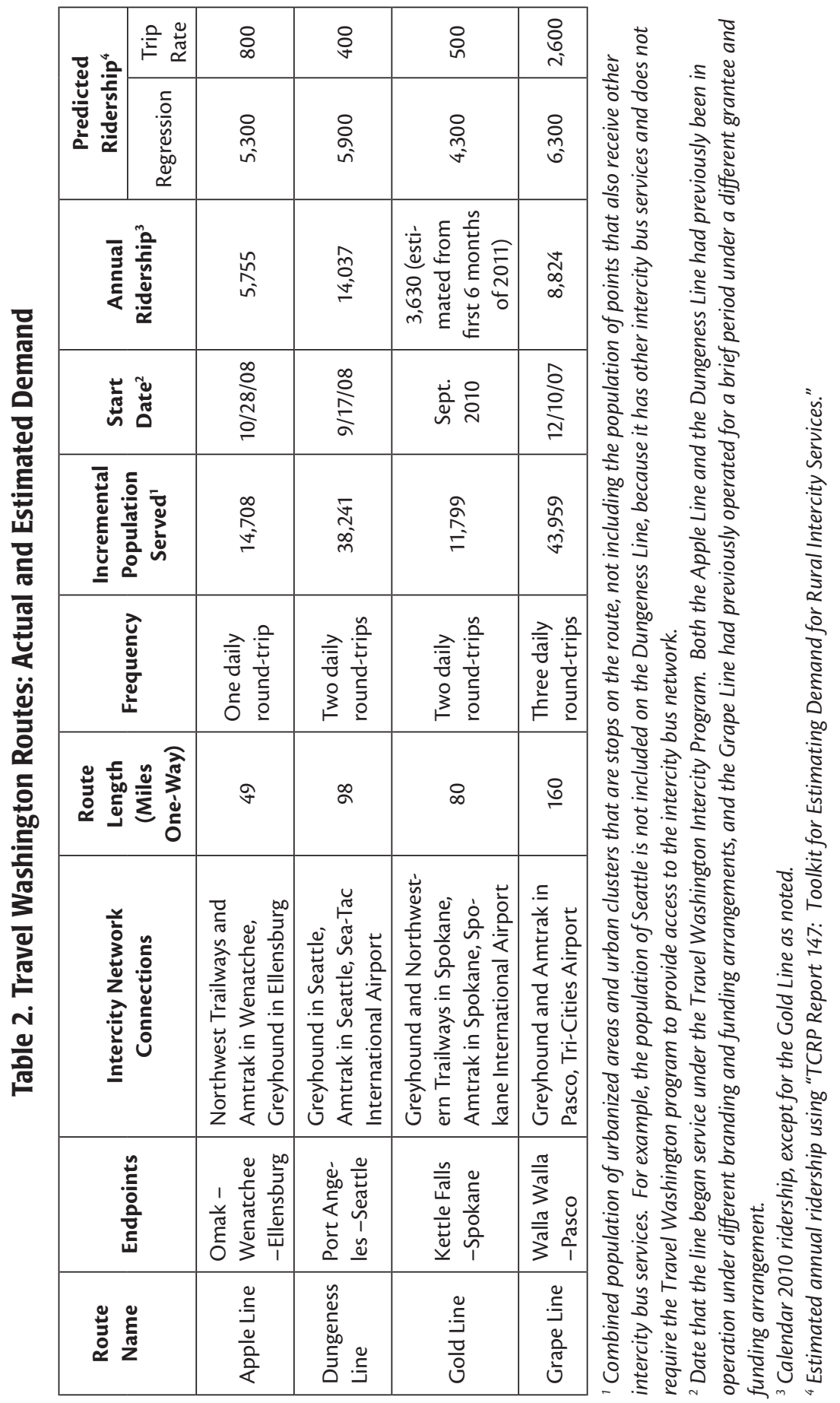


matic, with 50 places receiving intercity bus service in $1998,{ }^{8}$ declining to 6 places with such service today.

The arrival of Megabus services did not add any small towns to the intercity map, as Megabus serves only the largest city in the state, Burlington, with express services to Boston and New York City. Other intercity services include Greyhound Lines, with five stops, and Yankee Trails, with one stop. Given that there is a concentration of remaining service in Burlington and in the Lebanon-Hanover (New Hampshire)White River Junction (Vermont) urban cluster, a possible policy change for Vermont would be to use Section 5311(f) rural intercity funding for rural intercity routes from various points in the state to connect to these hubs for onward service to New York, Boston, Montreal, Albany, and other places that are both key regional destinations and connection points for other transportation services. Given a limited budget for such services, the state is interested in determining the likely ridership, potential revenue, and costs for such routes in order to focus limited resources most efficiently. The TCRP 147 rural intercity demand toolkit was used to estimate ridership for a number of corridors, as can be seen in Table 3.

As in the case of Washington, the regression model generally produced higher predictions of ridership, though in cases in which the proposed service would not be provided by a national intercity bus operator and would not serve an airport, low population corridors generally had regression predictions that are lower than the trip rate results. Only one of these corridors is currently in operation, the White River Junction to Springfield, Massachusetts, service operated by Greyhound. No ridership data are available, but based on the revenue per mile data provided by that firm, the estimated regression ridership is likely to be slightly below the actual ridership.

Table 3 illustrates that the toolkit can assist in service design, particularly the choice of operator and decisions about serving airports. The regression model in the toolkit reflects that fact that services provided by a national intercity bus carrier were generally found to have higher ridership, probably because of the fact that such services are fully interlined in terms of ticketing and are included in the schedule information, telephone information, and websites of the carriers. This allows inbound and outbound passengers to know about the service and buy tickets, resulting in a higher ridership base. 


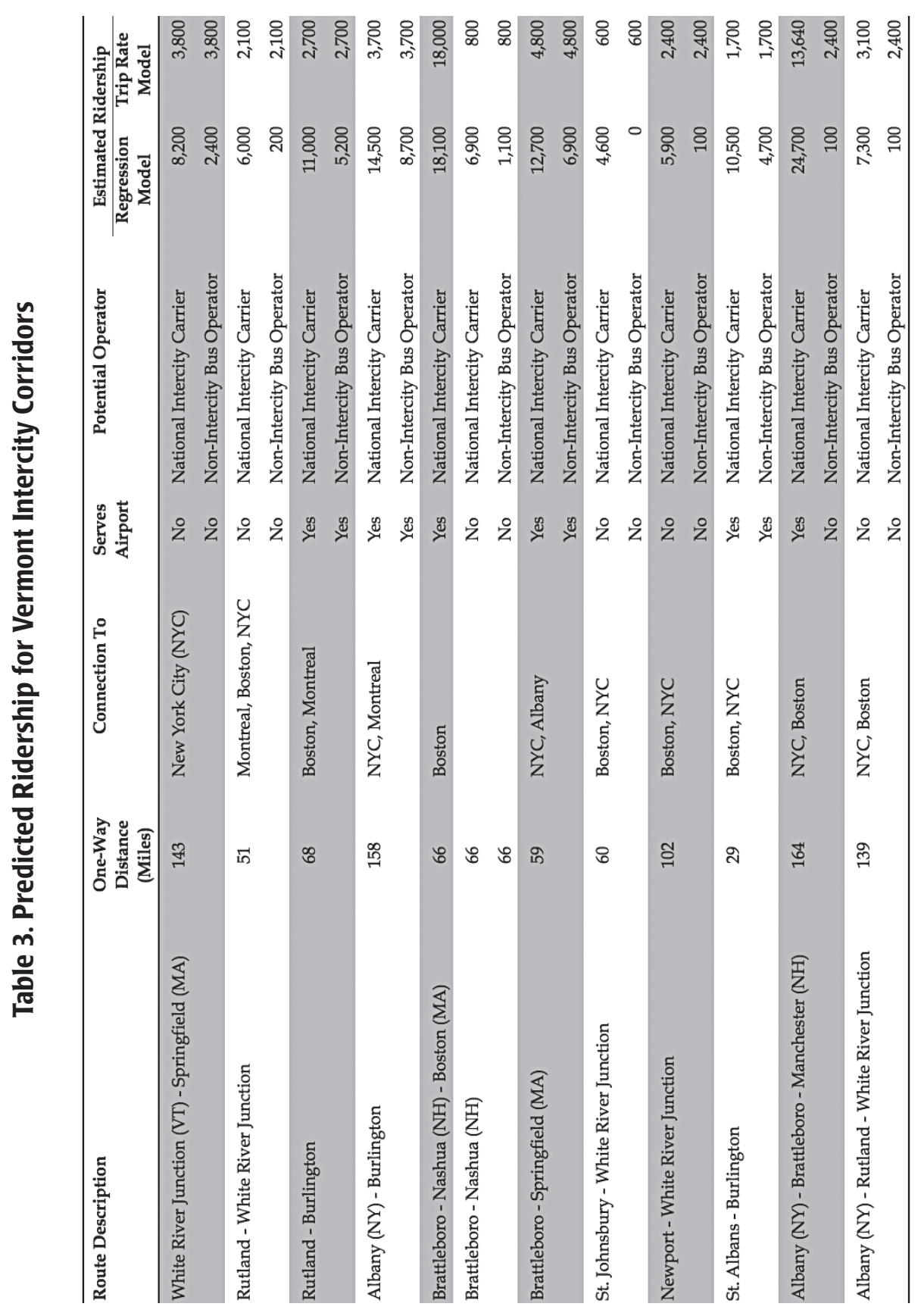


The demand estimates developed using the model are potentially most useful not just by themselves, but as part of an overall comparison of potential routes or route segments in terms of cost-effectiveness. However, the demand estimate is just one element of such an overall planning process. Once a ridership estimate has been developed, it is necessary to convert the ridership into an estimate of revenue. Typically, planning efforts have done this in the past by multiplying the ridership times an estimated average (national) intercity bus fare per trip. Alternatively, it would require estimating the average trip length for the passenger to estimate passengermiles and then multiplying that figure times a revenue-per-passenger-mile figure.

The other element of using ridership as part of an overall comparison of costeffectiveness is the estimation of costs to operate the route or service in question. Costs are likely to differ among types of firms, with national carriers having higher costs than local or regional firms and potential differences between public and private carriers. The source for recent data on projected revenue per trip or per passenger-mile and carrier operating costs is likely to come from the Federal Transit Administration (FTA)-required consultation process or from recent carrier grant applications.

To planners developing services, the higher potential ridership for a national carrier (as predicted by the model) is one reason to prefer a national carrier; at the same time, the higher operating costs of such firms may offset that advantage. For longer routes with high ridership, contracting with a firm that is part of the national intercity bus network may be necessary to provide peak capacity, but for shorter routes the optimal solution may involve contracting with local carriers or public transit providers that have lower operating costs but requiring them to be fully interlined with national networks to maximize ridership to and from the national network. If the ridership benefit from being part of the national network can be combined with lower costs, operating assistance requirements can be minimized.

Similarly, the potential additional ridership that could result from serving an airport can be compared to the potential additional costs of such service in terms of time and miles (and airport access costs).

Finally, the toolkit can be used to evaluate particular situations that may affect potential ridership. For example, in the Burlington-Albany corridor, the predicted ridership is 14,500 using the regression model. However, Megabus now operates express services from Burlington to New York City with a stop just north of Albany. These services may have taken all the passengers from that route who are destined for New York. The impact of such a scenario can be tested by eliminating Burling- 
ton from the model inputs. The model procedure already eliminates the population of the "destination" city, Albany, as it is the city with the largest population on the route. It is removed to reflect the fact that it likely already has substantial intercity service. To adjust the model result to reflect the potential impact of the Megabus service, the user can also drop Burlington so that the predicted ridership reflects only the intermediate towns. In that case, the predicted regression ridership falls to 11,700 .

\section{Conclusions and Directions for Further Research}

The toolkit models provide a tool that can be used as part of an overall planning process to evaluate potential routes. The two methods produce different results that can be used to create conservative scenarios for funding decisions and to test the impact of alternative service providers and airport service. The results are based on national data and provide order-of-magnitude predictions.

The two models developed in this process are limited in that they are not sensitive to changes in fares or frequency and that they do not account for ridership that might arise from population not directly served by the route-for example, through passengers who use the service because it bridges two other routes or riders coming from other modes or going to places with no population (parks, for example). The trip rate model relies on data from the previous NHTS, and the population data are from the 2000 Census, so an update needed.

Directions for future research on intercity bus demand could include additional effort to obtain data on more routes, particularly as the Section 5311(f) program expands. Models to predict demand at a stop would also be useful, as would tools that could allow planners to gauge the impacts of higher frequencies or lower fares. The impact of the availability of long-term parking at stops or terminals is another factor that could be considered in future research. Finally, a major step in developing a tool for estimating intercity bus demand generally would be a network model that would allow for the inclusion of overhead ridership, facilitating the estimation of demand for service to fill network gaps as well as serve populations on a route.

However, it should be noted that demand is only one factor in analyzing potential services. Another potentially useful direction for research is the development of the remainder of the rural intercity bus planning process, including techniques and factors to convert estimated ridership into revenue estimates, estimate operating 
costs, calculate subsidy needs, and provide performance measures to facilitate comparisons among alternatives.

\section{Endnotes}

${ }^{1}$ Schwieterman and Fischer, "The Intercity Bus: America's Fastest Growing Transportation Mode, 2010 Update on Scheduled Bus Service," Chaddick Institute for Metropolitan Development, DePaul University December 20, 2010, p. 3.

${ }^{2}$ Fravel, et al., "TCRP Report 147: Toolkit for Estimating Demand for Rural Intercity Bus Services," Transportation Research Board, Washington, D.C., 2011.

${ }^{3}$ Fravel, TCRP Report 147. Chapter 2 discusses the previous demand modeling techniques.

${ }^{4}$ In a regression equation, the term R-squared refers to the fraction of the sample variance of the dependent variable that is explained by the regressors. Adjusted $\mathrm{R}$-squared is a modified version of R-squared that does not necessarily increase when a new regressor is added to that regression. In general, a higher value of R-squared means that the model has more explanatory power. See pp. 193-195 in Stock and Watson, Introduction to Econometrics, 3rd Edition, 2010.

${ }^{5}$ As defined on the Toolkit CD, these are rural intercity routes provided in the traditional intercity model, generally with low frequencies (one daily round-trip or less), comparable distance-based fares (\$0.10 to $\$ 0.17$ per passenger-mile), interline ticketing (through the National Bus Traffic Association), information about connections through national bus information systems (Russell's Guide, Greyhound telephone/on-line information, etc.), generally operated by private for-profit firms.

${ }^{6}$ Stock and Watson, pp. 190-191.

${ }^{7}$ Burkhardt and Riese, "Estimating Travel Demands for Intercity Bus Routes," presented at the Transportation Research Board 61st Annual Meeting, Washington, D.C. January 1982.

${ }^{8}$ KFH Group, Inc., "Vermont Statewide Intercity Bus Study," prepared for the Vermont Agency of Transportation, 1998, p. 2-1. 


\section{References}

Burkhardt, Jon E., and Jeffrey I. Riese. 1982. Estimating travel demands for intercity bus routes. Presented at the Transportation Research Board 61st Annual Meeting, Washington, D.C., January.

Fravel, Frederic D., Reyes Barboza, Jason Quan, and Jason Sartori. 2011. TCRP report 147: Toolkit for estimating demand for rural intercity bus services. Transportation Research Board, Washington, D.C.

KFH Group, Inc. 1998. Vermont statewide intercity bus study. Prepared for the Vermont Agency of Transportation: 2-1.

Schwieterman, Joseph, and Lauren Fischer. 2010. The intercity bus: America's fastest growing transportation mode, 2010 update on scheduled bus service. Chaddick Institute for Metropolitan Development, DePaul University, December 20: 3 .

Stock, James H., and Mark W. Watson. 2010. Introduction to Econometrics, 3rd Edition. Boston: Pearson Education.

\section{About the Authors}

Fred Fravel (FFravel@kfhgroup.com) is Vice President of KFH Group, Inc., and has 30 years of experience in transit planning and policy development, including efforts dealing with intercity bus planning and research, coordination, and consensus building and local public transportation operational and facility planning issues. He has extensive experience with the intercity bus industry and has been the project manager or principal investigator for more than 30 intercity bus planning studies. In addition to local and regional public transportation planning projects, he was the Principal Investigator for a number of TCRP projects, including TCRP Report 79, Effective Approaches to Meeting Rural Intercity Bus Transportation Needs; TCRP Report 179, Toolkit for Estimating Demand for Rural Intercity Bus Services; and NCHRP Research Results Digest 356, Analysis of State Rural Intercity Bus Strategies: Requirements for Utilization of S. 5311(f) Funding. He holds an M.R.P. in Regional Planning from the University of North Carolina and a B.A. in Interdisciplinary Social Science from Duke University and serves on the TRB Committee on Rural Public and Intercity Bus Transportation. 
ReYes BARBOZA, JR. (RBarboza@kfhgroup.com) is a Transportation Planner with KFH Group, Inc., and has extensive experience in local, state, and federal transit projects. His background includes state transit program development and management, transit planning, operations and organization assessments, policy and program analyses and development, grants management and data reporting, procurement, program budgeting, industry research and survey development, and administration. He has teamed with Mr. Fravel on several statewide intercity bus assessments and in conducting industry research. Recently, he developed and managed the Intercity Bus Program for the Maryland Transit Administration. He continues to provide technical assistance to this program, and the second grant cycle for services will start July 1, 2012. He earned an M.C.P. from the University of Pennsylvania and a B.A. from Stanford University. 